\title{
Presidential Views: Interview with David Vogan
}

Every other year, when a new AMS president takes office, the Notices publishes interviews with the outgoing and incoming presidents. What follows is an edited version of an interview with David Vogan, whose two-year term as president ends on January 31, 2015. Vogan is the Norbert Wiener Professor of Mathematics at the Massachusetts Institute of Technology. The interview was conducted in fall 2014 by Notices senior writer and deputy editor Allyn Jackson.

An interview with president-elect Robert L. Bryant will appear in the March 2015 issue of the Notices.

Notices: The first thing I would like to ask about is the PCAST report Engage to Excel. ${ }^{1}$ Reactions to that report started bubbling up while you were still president-elect. You and several other mathematicians wrote a statement that appeared in the Notices. ${ }^{2}$ Could you tell me your observations of the math community's reactions to the PCAST report?

Vogan: The PCAST report was a very nice example of how strongly and wonderfully the mathematical community can react. I am probably going to be unfair to many other people if I say that my recollection

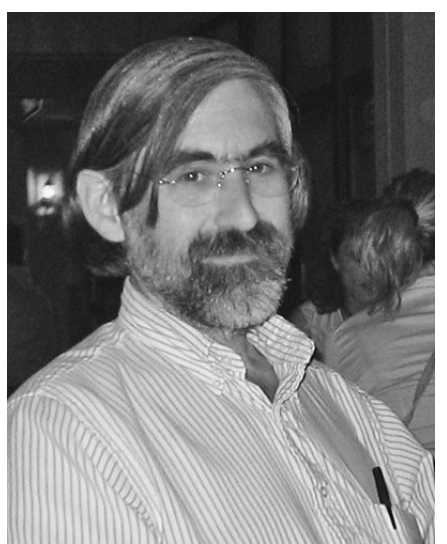

David Vogan is that Tara Holm, chair of the AMS Committee on Education, was really a driving force behind the statement that appeared in the Notices, which was a very reasonable reaction.

It seemed to a lot of mathematicians that the most important misunderstanding in the PCAST report was the idea that mathematicians didn't care about the obvious problems of students having difficulty with introductory math courses and

Allyn Jackson is senior writer and deputy editor of the Notices. Her email address is axj@ams . org.

${ }^{1}$ Engage to Excel: Producing One Million Additional College Graduates with Degrees in Science, Technology, Engineering, and Mathematics, a report by the President's Council of Advisors on Science and Technology, February 2012. See also "Presidential Report Draws Criticism from Mathematicians," by Allyn Jackson, Notices, October 2012.

2 "Mathematicians' Central Role in Educating the STEM Workforce", by Eric M. Friedlander, Tara S. Holm, John Ewing, Rebecca Goldin, William H. Jaco, T. Christine Stevens, Abigail Thompson, and David A. Vogan Jr., Notices, October 2012.

DOI: http://dx.doi.org/10.1090/noti1215 that mathematicians had no idea about what to do about these problems. In fact, in some sense, almost every mathematics department is doing something to address these issues. So the first big reaction was just to try to point to the fact that there were a lot of good things going on already and then to try to make some of those good things available widely across the community.

Maybe one problem is that some of the best things that are going on are hard to learn about and hard to copy. Traditionally, people who were really good at teaching wrote a textbook. Then anybody could use, say, Nathan Jacobson's graduate algebra text, and Jacobson's understanding of how you should explain that kind of algebra became widespread. This was a wonderful system. A lot of the changes that are being developed now might have less to do with the content of what's being taught and more to do with the form and with the way things happen in a classroom. It is certainly more difficult to put those things in a textbook. The result is that we haven't understood well how to pass them around. So there is a lot of activity now trying to address that-to see how the people who have figured out great things about teaching at an elementary level can share what they do.

I should certainly mention the group that Eric Friedlander, Phillip Griffiths, and Mark Green started, called TPSE, Transforming Post Secondary Education in Mathematics. This also is aimed at highlighting new ideas about teaching mathematics and implementing them widely.

For many years the Committee on Education has had during its annual meeting an event for department chairs that offers interesting and useful information about math education. This year, Tara 
Holm organized a meeting that had presentations by seven or eight speakers who talked about things that they were doing to address issues in beginning mathematics education. There was a huge amount of discussion: What can I do in my department? How do I go about taking advantage of these ideas? There have been panels at the Joint Math Meetings of a similar nature, also very well attended and inspiring a lot of discussion.

Notices: During your presidency, the AMS started two new open access journals: the new series of the Transactions and the Proceedings. What are your observations about how that is going?

Vogan: It went very smoothly. The only thing that has been disappointing about the journals is the level of response from authors. There is quite a bit of funding available in universities to support page charges in open access journals, because a lot of libraries see this as a reasonable thing for their budgets. The AMS hoped that with a new venue and the possibility of slightly improved publication times, people might be willing to make the extra effort to find out whether they had access to these resources. But not many have made this effort. The first time you try to figure out how to get your university to produce money for such page charges, it's a pain and takes time, but every other time you do it, it's easy. So I hope that the number of people who are able to take advantage of this will grow.

There was also a concern at the time the journals were launched that the UK was considering policies that could make open access publishing a requirement for UK-funded research. There was concern that such policies could be implemented in the US and elsewhere. If this kind of open access requirement goes into place anywhere, we are now at least in a position to continue publishing work from those places. The size of the journals is so far a bit of a disappointment, but I think that the reasons for setting up the option were sound and that it was done very well.

Notices: Any other observations on the publishing front from your time as president?

Vogan: I think the staff and the volunteer structure in the AMS are fairly united in thinking that the AMS should publish more mathematics, especially more research journal pages. There isn't a clear consensus about how to do this, but I think many people are coming to like the idea of having another large general research journal, with no restriction on field. That's not something that is going to happen next week or next year, but I think that the Committee on Publications is very amenable to such an idea and is starting to think about what would be involved in making it happen. People like the way the AMS does journal publishing. The prices are good. The backlogs are a pain, but the backlogs are there because there is more good mathematics to publish than we currently have the capacity to handle. Apart from the backlogs, people are quite happy with the way the AMS does publishing.

Notices: The Notices has hosted a discussion of the revelations of Edward Snowden about the NSA [National Security Agency]. Can you tell me about how you see mathematicians' reactions to this issue? A reading on how the math community thinks about it?

Vogan: That's a really tough question. What I have come to understand is that a very large fraction of the math community sees these questions very differently from how I do. I have tried to understand what the general views are, but it's been a very difficult process for me. What I think is that a lot of mathematicians see the work that's done by mathematicians at the NSA as building absolutely necessary tools; maybe sometimes these tools have been abused, as almost any tools can be, but that doesn't affect the need to build the tools. I think most mathematicians view the work of building those tools as honorable and important mathematical work.

Notices: Not so many people seem interested in participating in the Notices discussion. I have the impression people are not too concerned.

Vogan: I think they are not concerned about the mathematical aspects of the question. People may have issues with the way the executive branch [of the US government], for the past ten years at least, has been using these tools. But they don't have issues with the mathematical work underneath. I really liked Tom Hales's article in the Notices. ${ }^{3}$ That article described mathematical work that should never have happened. He described work that was done using, not incredibly deep mathematics, but nevertheless using mathematics in a way that was just a mistake. There wasn't a justification for doing it. Hales made it clear that it has not been proven that NSA did what he described as a possibility. But what he described seemed to me to be using mathematics to lie and cheat, to make people believe things that were not true. And I don't see that as an acceptable way to use mathematics.

Notices: One thing we talked about in the previous presidential interview is the future of the AMS membership. We talked about how the AMS can

\footnotetext{
3 “The NSA Back Door to NIST," by Thomas C. Hales, Notices, February 2014.
} 
reach out to young people and encourage them to become members and participate in the Society. What are your thoughts on this two years later?

Vogan: It's still a serious issue. I am quite happy that it is one of the central themes of the strategic planning process that the AMS is now undertaking.

In getting ready for this interview, I looked at agendas for various committee meetings. One of the things in a bunch of the agendas is: How do we make the lectures at AMS meetings more accessible? And, more generally, how do we make mathematics more accessible? How do we make mathematics accessible to other mathematicians, to our students, to the world at large? This is something that is worked on constantly, and it is something that almost all mathematicians care about. Working on those issues in a good way, in a successful way, makes this an attractive organization.

If I open up MathSciNet now, next to any of the articles that are listed, there is a little button that says "Get this at MIT". I'm not completely sure how widespread these buttons are, but they are spreading, and they are making MathSciNet an even more powerful and useful tool. That's one big change. There have been many changes in MathSciNet. MathSciNet is a work in progress and gets better all the time. I think if we make tools like that, if we continue to make them more useful for all mathematicians, and in particular young people, then that's an aspect of making the organization more appealing.

Notices: Is there anything else you wanted to talk about that we didn't cover or anything that happened during your presidency that you wanted to comment on?

Vogan: I really liked a couple of transitions. The Membership and Professional Services Department at the AMS has in my mind been identified with Ellen Maycock for a very long time. She was what made that department a wonderful thing. Last summer, she began the process of retiring, and Chris Stevens stepped into that job. The department is going to be a little bit different, because Chris Stevens is different from Ellen Maycock, but it's going to continue to be wonderful. It's a great thing that this institution has continuity beyond the individuals that make it up. Also at Math Reviews, executive editor Graeme Fairweather retired at the beginning of June, and it was really unclear how we were going to find somebody to take over that enormous and really difficult job. And now Ed Dunne [formerly an AMS acquisitions editor] is doing it. There again, things are going to look different, and they are going to look great. Next February I am not going to be the president of the AMS; a wonderful, experienced new person is coming in. Things are going to be different, and they are going to be better.

Notices: What was the most important thing you learned in your time as AMS president?

Vogan: [laughs] Probably Sheila Rowland's email address [Sheila Rowland is a longtime AMS staffer in the Executive Director Department]. The staff of the AMS is just a fantastic thing. I admire the staff in a lot of math departments; they are fantastic and indispensable. But what goes on at the AMS is a whole different thing. From Don McClure and Sheila Rowland to Ed Dunne and Robin Marek [AMS development director] and Sandy Frost [now retired Notices managing editor]-every name that comes into my head makes me smile and makes me think about the way these people do the work of supporting mathematics. It's a fantastic thing.



\section{ICERM Director Search Announcement}

The Board of Trustees of the Institute for Computational and Experimental Research in Mathematics and Brown University seek a new institute Director for an appointment to begin between August 2015 and July 2016. The Director will serve as the scientific and administrative leader of ICERM and will be a distinguished member of the Brown faculty.

The successful candidate will possess outstanding scholarly credentials, including a Ph.D., as well as demonstrated academic leadership experience. The Director will hold a tenured position at Brown University in the Department of Mathematics or the Division of Applied Mathematics, or jointly in at least one of these departments. Preference will be given to applicants whose research interests align with the mission of ICERM. The term of the appointment as Director of ICERM ends August 2020, and may be renewed.

For more information go to: http://icerm.brown.edu/home/index.php\#jobs

Brown University is committed to fostering a diverse and inclusive academic global community. 